\title{
Potential potassium protection
}

Potassium-channel openers - drugs that promote the influx of potassium - might help protect heart cells (myocytes) against damage from heart attack, proposes a study on guinea-pig myocytes, published in the 1 November issue of Science. Brian O'Rourke and colleagues have discovered a new type of potassium channel in the membrane of myocyte mitochondria, and have shown that a drug that opened the channel protected isolated rabbit hearts against tissue death and low oxygen conditions caused by a heart attack.

Despite the great benefits seen in major trials of the use of thrombolytic therapy and various adjunctive treatments, such as beta-blocker therapy and angiotensin-converting enzyme (ACE) inhibitors, ischaemic heart disease and myocardial infarction (heart attacks) remain the largest cause of death in developed countries.

Ions traverse the plasma membrane of cells through channels created by embedded transmembrane proteins, driven by an electrochemical gradient between the extracellular and intracellular contents. Ion channels on the mitochondrial inner membrane similarly mediate ion flow between the cytoplasm and the mitochondrial matrix compartment, and influence myocyte cell function in diverse ways. The mitochondrial ATP-sensitive potassium channel ( mitoK $_{\text {атр }}$ ) has an instrumental role in protecting myocytes from necrotic and apoptotic cell death, whereas other channels contribute to mitochondrial dysfunction.

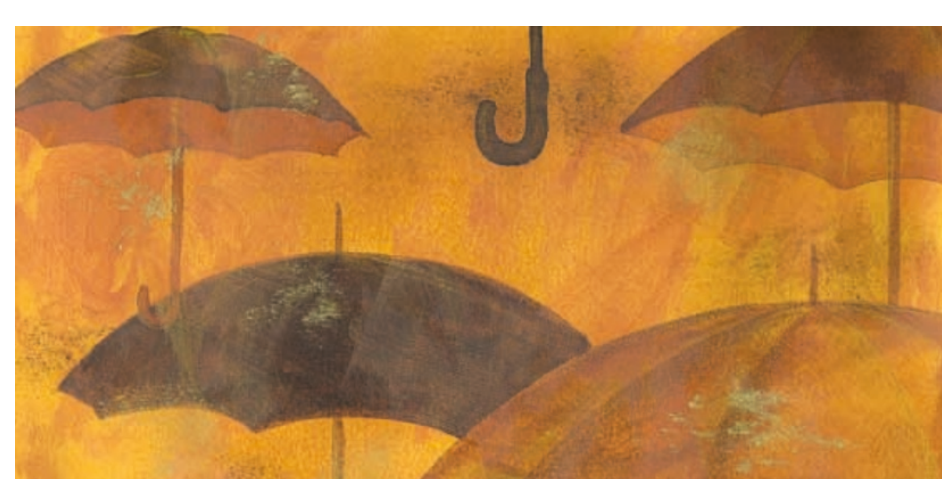

Drugs that block the flow of calcium ions into heart muscle cells, such as verapamil or diltiazem, are known to treat various heart conditions, but a growing body of evidence indicates that encouraging the flow of potassium across certain membranes inside heart muscle cells might be useful as well.

The newly identified mitochondrial potassium channel $\left(\right.$ mitoK $\left._{\mathrm{Ca}}\right)$ was activated by calcium ions, and had similar properties to the cellmembrane calcium-activated potassium channel. The authors showed that a significant portion of potassium passes through the mitoK $\mathrm{K}_{\mathrm{Ca}}$ channel into the mitochondria.

The authors speculate that the function of mitoK $_{\mathrm{C}}$ could be to improve the efficiency of mitochondrial energy production when cellular calcium levels increase, because potassium ions are required for optimal oxidative phosphorylation - a necessity for respiration. Potassium ions might also modulate other mitochondrial functions, such as the production of reactive oxygen species. Although opening mitoK $\mathrm{K}_{\mathrm{c}}$ protects against ischaemic injury in animal models, it remains to be seen if the same is true in humans.

Melanie Brazil

(2)) References and links ORIGINAL RESEARCH PAPER Wenhong, $X$ et al. Cytoprotective role of $\mathrm{Ca}^{2+}$-activated $\mathrm{K}^{+}$ channels in the cardiac inner mitochondrial membrane. Science 298, 1029-1033 (2002) FURTHER READING O'Rourke, B. Myocardial K(ATP) channels in preconditioning. Circ. Res. $87,845-855$ (2000)

\section{WEB SITE}

oratory:

http://www.jhmi.edu/ bor/
O'B SITE

\section{IN BRIEF}

\section{ANTIBACTERIAL DRUGS}

Fleming's unfinished.

Wainwright, M. Perspect. Biol. Med. 45, 529-538 (2002)

Just as music historians complete the unfinished symphonies of composers, Milton Wainwright has pieced together findings from Alexander Fleming's lab books, which could help restore the much-maligned reputation of the discoverer of penicillin. Far from being a lazy researcher who lost interest in his discovery, but was happy to take most of the credit for it becoming a medical breakthrough, Fleming's lab notes reveal that he spent many years meticulously screening airborne moulds for antibiotic properties, and made possibly one of the first observations that bacteria can develop resistance to antibiotics.

\section{PROTEIN FOLDING AND DISEASE}

\section{Absolute comparison of simulated and experimental} protein-folding dynamics.

Snow, C. D., Nguyen, H., Pande, V. S. \& Gruebele, M. Nature 420, 102-106 (2002)

One reason that it is so difficult to predict the shape (and therefore function) of a protein from its amino-acid sequence using computers is because folding occurs in the order of microseconds in the cell, but it takes an average computer 1 day to simulate only 1 nanosecond of folding. Snow and colleagues used a program called Folding@Home to distribute small portions of the calculations of the folding of an artificial 23-amino-acid mini-protein called BBA5 among the screensavers of 30,000 computers. Secondary structures and the folding rates were all consistent with the available experimental evidence, and the formation of several intermediates confirmed the heterogeneous nature of protein folding.

\section{ADRENOCEPTOR PHARMACOLOGY}

Pharmacological characterization of CGP 12177 at the human $\beta_{2}$-adrenoceptor.

Baker, J. G., Hall, I. P. \& Hill, S. J. Br. J. Pharmacol. 137, 400-408 (2002)

The class of drugs known as beta-blockers, long known for their hypotensive benefits, are increasingly being used for the chronic treatment of congestive heart failure, and also seem to have potential for treating inflammatory airway disease. The mechanism of action of beta-blockers in these newer indications is unclear. Here, Stephen Hill's group present evidence that a wellknown, high-affinity 'beta-blocker', CGP 12177, which has already been shown to have agonist activity at the $\beta_{1}$-adrenoceptor, also has partial agonist behaviour at the $\beta_{2}$-adrenoceptor. This adds weight to the possibility that some of the newly observed effects of this group of drugs might in fact arise from receptor activation, rather than the presumed deactivation. 